\title{
Ensinando sobre a diferença na literatura para crianças: paratextos, discurso científico e discurso multicultural*
}

\author{
Rosa Maria Hessel Silveira \\ Universidade Federal do Rio Grande do Sul, Programa de Pós-Graduação em Educação \\ Universidade Luterana do Brasil, Programa de Pós-Graduação em Educação
}

\section{lara Tatiana Bonin}

Universidade Luterana do Brasil, Programa de Pós-Graduação em Educação

\author{
Daniela Ripoll \\ Universidade Luterana do Brasil, Programa de Pós-Graduação em Educação
}

\section{Esboçando o contexto do estudo: literatura para crianças e a temática das diferenças}

São bastante conhecidas as estreitas relações entre a literatura para crianças e a pedagogia. Tais relações tanto têm sido focalizadas nos ensaios acadêmicos quanto aparecem, de forma recorrente, sob a roupagem de expressões cotidianas da vida escolar. "Usar uma história para discutir um caso", "encontrar um livrinho que trate do problema X", "trabalhar frações de forma lúdica com uma obra" são justificativas hipotéticas semelhantes às que frequentemente ocorrem no ambiente escolar, mesmo que, em contrapartida, os críticos e especialistas em literatura infantil costumem alertar para o que seria o desvirtuamento do sentido central da própria literatura - a literariedade, o inusitado, o lúdico e o estético. ${ }^{1}$ Surgida em articulação com o próprio conceito de

*Este artigo é resultado do projeto de pesquisa "Narrativas, diferenças e infância contemporânea", apoiado pelo CNPq com Auxílio-Pesquisa e Bolsa de Produtividade em Pesquisa.

${ }^{1}$ Para uma abordagem mais detida dessa questão, ver Kirchof e Silveira (2008). infância, conforme Shavit (2003) relembra, a literatura para crianças tem estado, de diferentes formas, imbricada com a escola. Se, por um lado, ela depende de a escola produzir seus destinatários leitores, por outro lado tem servido, conforme os diferentes ideários inspiradores dos planos curriculares, como pílula edulcorada para formar, informar, ensinar e conformar. Mais especificamente, Ferreira (2006, p. 146), em relação à literatura brasileira para crianças, num quadro que não difere muito de outras nações ocidentais, observa:

[...] até a década de 1960, valores como o enaltecimento à pátria, à família, obediência e respeito aos mais velhos, noções de higiene etc. eram intensamente presentes na produção destinada à criança. Após o processo de renovação da literatura para criança, que no Brasil ocorreu a partir dos anos $1970[\ldots]$, outros valores emergem, como, por exemplo, ser crítico em relação ao modo de ser da classe dominante, ser criativo, ser bastante informado, ser contestador das regras tradicionalmente estabelecidas, entre outros.

Demonstrando, mais uma vez, a sempre renovada aliança entre a literatura para crianças e o aparato escolar, a autora (idem, ibidem) registra ainda: 
[...] mais recentemente, apoiados nas orientações educacionais em nível nacional (Parâmetros Curriculares Nacionais, 1998), alguns livros infantis foram produzidos enfatizando valores como: aceitação à pluralidade cultural, respeito à sexualidade, defesa pelo equilíbrio do ecossistema.

Tomar a criança leitora como um ser em formação e, portanto, como alvo de nossos intuitos adultos de inseri-la em nosso sistema de valores tem sido uma constante na literatura para crianças, mesmo que sua incorporação à educação, como apontou Ferreira, adquira matizes diversos, correspondendo a mudanças de atitudes pedagógicas. Colomer (2003) relembra dois princípios básicos de adequação dessa literatura a seu destinatário último: a conveniência educativa e a compreensibilidade do texto. De certa forma, desses princípios resulta a existência de um "duplo destinatário": a literatura infantil "supõe a criação de textos que, embora destinados às crianças, são sancionados pelos adultos" (idem, p. 164). E, entre esses adultos, podemos situar tanto mães, pais e outros familiares como os responsáveis pela educação formal letrada: professores, bibliotecários, supervisores e, em alguma medida, os próprios especialistas da área.

Essa ambivalência de destinatário é um dos focos de nossa atenção na escolha do material e na análise que realizamos neste estudo. Tomaremos como objeto de nosso exame especificamente alguns tipos de paratexto de larga ocorrência nos livros infantis atuais. Para tanto, entendemos paratexto como

\footnotetext{
O conjunto de fragmentos verbais que acompanham o texto propriamente dito; pode se tratar de unidades amplas (prefácios, textos figurando na capa etc.) ou de unidades reduzidas: um título, uma assinatura, uma data, um intertítulo, uma rubrica [...], comentários na margem. (Maingueneau, 2001, p. 81)
}

Nos livros infantis, alguns tipos de paratex$\operatorname{tos}^{2}$ são mais frequentes que outros (prefácios, por

${ }^{2}$ A opção por usar paratexto no plural embasa-se em usos correntes encontrados na bibliografia e serve ao intuito de distinguir diferentes segmentos que circundam um mesmo texto principal: biografia do autor, sinopse, dedicatória etc. exemplo, são raros), justamente tendo em vista o que Charaudeau e Maingueneau (2004, p. 367) chamam de condições da comunicação, em que se mesclam o código social (publicitário) e os códigos produtores ou reguladores do texto. Mesmo que não integrem o cerne do livro - que seria constituído pela apresentação de uma narrativa por meio da junção texto verbal/texto imagético -, os paratextos não deixam de definir expectativas de leitura e intenções editoriais (francamente educativas, como veremos), e, de certa forma, comandar a escolha do livro (em especial pelo destinatário adulto) e sua leitura.

Assim, é comum que nos livros para crianças - e aqui nos detemos naqueles destinados a crianças dos últimos anos da educação infantil e dos anos iniciais do ensino fundamental - encontremos, ora na $2^{\underline{a}}, 3^{a}$ ou 4 $4^{\mathrm{a}}$ capa, ora nas orelhas, ora nas páginas finais ou iniciais do volume, dedicatórias, biografias de autores e ilustradores, notas explicativas sobre algum aspecto abordado ficcionalmente no texto principal, glossários, breves apresentações da série a que o livro pertence ou, ainda, sinopses com tom persuasivo, apresentando a história trazida pela obra. Também é relativamente comum a presença de suplementos encartados para "trabalho em sala de aula", obviamente destinados para o interlocutor adulto, com um olho no aproveitamento pedagógico que a criança deveria "fazer" da obra.

Se nos voltarmos para as temáticas que, nos últimos anos, tanto no panorama brasileiro quanto no ocidental em geral, têm invadido a literatura para crianças, deparamo-nos com a questão das diferenças, o que, evidentemente, não é algo casual. A visibilidade que tal temática adquiriu, sob roupagens diversas, desde a invenção norte-americana do "politicamente correto", relaciona-se com discursos multiculturais, pós-coloniais, pós-estruturalistas, todos com significados, objetivos e efeitos bastante diversos, ou seja, o discurso da diversidade e da diferença espalhou-se de forma tentacular no tecido social, alimentado pela redefinição do conceito de cultura, pelos impactos de movimentos sociais de reivindicação de direitos de grupos tradicionalmente oprimidos, pelo fim de empreendimentos colonialistas, por alguns avanços da 
ciência que permitiram questionar a "naturalidade" de certas características atribuídas a uns e outros povos ou sujeitos, pelo enfraquecimento de ideários como o da eugenia, por exemplo.

Além disso, a concepção do discurso como constituidor da própria realidade, resultante da chamada virada linguística, trouxe novos argumentos para as discussões sobre a diferença. Dentro de tal concepção, entende-se que as maneiras de falar sobre as coisas, os acontecimentos e sujeitos não são formas neutras de descrição, mas participam na produção daquilo que descrevem e apresentam. Para Hall (1997), dentro da linguagem não há um significado final ou verdadeiro, mas significados construídos e negociados que, ao circular, constituem identidades a partir de regras que definem o que pode ser dito, quando, de que maneira e quem tem autoridade para fazê-lo.

A eclosão e a visibilidade das diferenças também têm sido apropriadas pelas redes de consumo, produzindo-se, por um lado, toda uma pletora de produtos e serviços destinados aos "diferentes", em uma estratégia de segmentação (e proliferação) de mercados, e, por outro, todo um amplo leque de textos comunicacionais abordando os grupos minoritários. Para Yúdice (2006), a importância dada à diferença poderia ser vinculada a uma crescente tendência de comercialização da experiência e do desejo na atualidade. Nesse sentido, não se trata apenas de transformar a diferença em mercadoria, mas de potencializá-la, de torná-la espetáculo, de conferir-lhe certo sentido sedutor, de convertê-la em algo novo, desejável, celebrativo.

A hipótese de que as transformações culturais e sociais têm sempre reflexo no panorama educativo ganha mais uma vez um argumento favorável, ao identificarmos como o discurso da diversidade e da diferença invadiu os espaços escolares e de entretenimento para crianças e jovens. Os livros didáticos, os desenhos animados, as histórias em quadrinhos, os livros para crianças tornam-se veículos para tais abordagens, ao mesmo tempo que, no próprio terreno da legislação educacional, se tomam medidas de alguma forma relacionadas com a diferença: estão aí presen- tes os Parâmetros Curriculares Nacionais (PCNs), a instituição das cotas, as políticas de inclusão e, como estamos vendo, os livros de literatura para crianças, tão almejados e utilizados nas escolas de educação infantil e ensino fundamental.

Pois bem, para o presente trabalho, partimos da constatação da onipresença e da visibilidade da literatura infantil no cenário pedagógico e do pressuposto de que os paratextos que nela ocorrem são importantes guias para a sua leitura. Consideramos, por outra vertente, que a diferença, sob qualquer de suas dimensões (idade, deficiência, etnia, imagem corporal etc.), como tema de interesse contemporâneo, tem invadido a literatura infantil. A partir de tais parâmetros, traçamos como objetivo para o presente trabalho analisar as diferentes formas como esses paratextos também se alinham a uma dimensão pedagógica, ensinando e buscando influenciar condutas e atitudes. Para desenvolver o trabalho, tomamos como objeto de análise alguns dos paratextos pertencentes a 19 livros de 10 coleções e uma série de literatura infantil que abordam a diferença, assim como dois títulos avulsos que trazem idêntica temática. Detivemo-nos especificamente em paratextos que, localizados em diversas posições do livro, trazem justificativas para sua leitura e outras explicações que os autores e editores julgaram conveniente adicionar.

É preciso considerar, ainda, outros aspectos. Assim, o desenvolvimento da indústria editorial e de outras mídias, como a internet, a televisão e o cinema, repercutiu numa maior sofisticação das edições impressas, ao mesmo tempo que o interesse mercadológico de divulgação e venda dos livros infantis passou a implicar maior investimento em estratégias de captação dos destinatários - o adulto, em primeiro lugar, e a criança, em segundo; ambas as dimensões provocaram o aumento sensível da quantidade de paratextos em tal tipo de literatura. Uma vez que as dimensões do presente trabalho nos impedem uma exploração mais aprofundada dos recursos de que lançam mão todos os paratextos, deter-nos-emos na análise de dois discursos que perpassam grande parte deles: o discurso multiculturalista e o discurso científico. 


\section{Ecos de um discurso multiculturalista}

Em primeiro lugar, observamos que nas obras de literatura infantil que tematizam a diferença também se reafirma a histórica preferência do gênero pela utilização de animais como personagens: são joaninhas diferentes, coelhos de orelha quebrada, pássaros gordos ou que não sabem cantar, patinhos feios (Andersen teve seguidores!), ovelhas negras e elefantes coloridos, entre outros. Os animais protagonizam aventuras e conflitos, enfrentam dificuldades e sofrimentos, aprendem e ensinam nas tramas de cada história. A escolha de animais (ou, em alguns casos, de objetos) como protagonistas é um recurso metafórico utilizado para abordar de maneira atenuada algumas temáticas conflitivas. Em parte das obras, tais personagens parecem estabelecer uma vinculação entre as diferenças e as coisas que reconhecemos como "naturais" - partes daquilo que chamamos de natureza e que, tradicionalmente, situamos em oposição à cultura.

Em algumas obras cujas histórias têm personagens humanos, os paratextos trazem os animais como termos de comparação, utilizados para explicar as diferenças em uma linguagem "científica" e, ao mesmo tempo, acessível aos pequenos leitores. Assim, em um livro que tematiza as diferenças de crianças com síndrome de Down, destaca-se, nas páginas finais, o seguinte paratexto:

O elefante tem tromba. A girafa tem pescoço comprido. A formiga é bem pequenininha. O ornitorrinco, nem se fala... tem uma cara que é só dele... Todo mundo é mesmo muito diferente. Basta olhar para os animais. Cada um do seu jeito, eles formam uma grande comunidade onde todos têm o seu espaço e vivem como querem, sem prejudicar o outro. [...] Ninguém nunca ouviu falar que a girafa tivesse brigado com o elefante por achá-lo fora do peso, ou que a formiga tivesse criticado o casaco afiado do porco-espinho... Afinal, tudo na natureza é legal por ser diferente! (Livro 12) ${ }^{3}$

${ }^{3}$ Neste artigo, os livros serão indicados por números, relacionados em lista ao final.
Em outra obra (Livro 17), que versa sobre as diferenças entre os membros da família, utiliza-se a metáfora da "árvore do mundo", para abordar a variedade entre as diferentes descendências. Ora, a alusão a elementos "naturais" nos textos explicativos (de forma referencial ou metafórica) sugere que identidades e diferenças sejam tomadas como coisas do domínio da natureza, e não como construções da cultura. $\mathrm{Na}$ análise de Bauman (2000), a perspectiva multicultural colabora para a naturalização das relações de força implicadas na produção das diferenças no momento em que considera que ser igual ou ser diferente é da ordem natural das coisas, pois assim também ocorreria com plantas e com (outros) animais. Em tal perspectiva, existiriam múltiplas formas de ser e de viver presumivelmente naturais e, dada a diversidade das sociedades, teríamos que aprender a relativizar certos conceitos para sermos tolerantes com as diferenças. Tal entendimento se conecta com um paratexto do Livro 13, em que se lê: "se todo mundo fosse igualzinho, o mundo não teria graça! Mas só reconhecer que as pessoas são diferentes não basta. É preciso respeitar as diferenças. [...] Assim ou assado, todos são gente, tudo é humano".

Tudo ocorre, então, como se a diferença fosse uma característica própria dos sujeitos e não efeito de relações de poder e de classificações que inventamos e que produzem hierarquização, posicionando em desvantagem aqueles que consideramos diferentes a partir de normas, valores e símbolos culturais da identidade na qual nos posicionamos. Contemporaneamente, os discursos multiculturais produzem, como tendência geral, uma positivação das diferenças, tomadas como essenciais, autorreferenciais, com valor em si mesmas. Mas tal entendimento também não problematiza as condições culturais e discursivas a partir das quais as diferenças são produzidas e reconhecidas como tal.

Conforme Bhabha (2005) e Hall (1997), o multiculturalismo tem sido alvo de muitas críticas: em primeiro lugar, por ressaltar o que há de superficial e externo nas culturas, descrevendo-as genericamente; em segundo, por celebrar e acolher uma diversidade que de certa forma é ordenada pelos discursos da 
cultura modelar; por fim, por considerar as diferenças como fragmentos de uma totalidade mais ampla como a nação, por exemplo.

Ao entender a diversidade como componente de algo maior, a perspectiva multicultural subordinaria certas identidades, tidas como periféricas, a outras posicionadas como centrais, o que possibilita falar, por exemplo, das "contribuições" de certos povos para a cultura central, destacando o que deles "herdamos". Uma ênfase a tais aspectos foi observada em paratextos como este: "Com seu berimbau mágico, [Luana] viaja para outras épocas e lugares, nos levando a aventuras incríveis. Entre outras coisas, ela mostra o valor de nossa herança cultural e a importância dos diferentes povos na formação de nosso país" (Livro 15). Um paratexto do Livro 11 fala da "diversidade de culturas e do colorido de raças que existem no Brasil". Na apresentação do Livro 20, destaca-se que ele "apresenta narrativas herdadas da rica cultura popular brasileira". Na capa interna da obra, registra-se que, "além de atualizar a linguagem, [o autor] quer recuperar a graça, o sabor, o movimento, a poesia das histórias folclóricas". Efetivamente, o que reconhecemos como "nossa herança cultural" é uma composição, assentada em uma perspectiva eurocêntrica, que posiciona de modo desigual as culturas que supostamente lhe deram forma; assim, a cultura nacional enriquecer-se-ia de aspectos periféricos dos outros - nesse caso, as tradições indígenas e africanas. Ora: somente nessa lógica é que faz sentido chamar as narrativas dos outros de "histórias folclóricas".

Em alguns paratextos examinados, entretanto, observam-se algumas rupturas com as perspectivas já discutidas. $\mathrm{O}$ fragmento a seguir parece considerar o caráter arbitrário e posicional das relações entre identidades e diferenças e o faz através de uma sequência de perguntas que acentuam a instabilidade das certezas.

Ser diferente - que mistério é esse, ser diferente? Todo o mundo é? Ou todo o mundo é igual? Tem gente que é igualzinha: os gêmeos univitelinos. Mas não inteirinha igual. E tem gente parecida [...] e tem então os diferentes.
Mas os diferentes sempre têm seus parecidos, e então não são diferentes. São parecidos com os diferentes. Quem são os mais diferentes? Depende de como eu sou. Mas, e se eu for muitos? Então vou ser parecida com muitos. Mas sempre tem um que todo mundo vai dizer que parece comigo. Enfim, iguais e diferentes podem ser diferentes e iguais. (Livro 21)

Outro aspecto que chama a atenção no conjunto de paratextos analisados é a ênfase no tratamento das diferenças como algo da esfera do cotidiano, e, para acentuar tal trivialidade e proximidade, afirma-se, por exemplo, que as diferenças "estão do seu lado todos os dias e você nem percebe" (Coleção E); ou que as histórias são "inspiradas em situações comuns do dia a dia" (Coleção J). O Livro 14 é apresentado da seguinte forma: "Essa é a história de um menino que busca um caminho para a sua vida, com as limitações de uma cadeira de rodas, e de como ele o encontra através de sentimentos maravilhosos que todos temos dentro de nós - e por vezes nem percebemos" (Livro 14).

Ao que parece, essa é uma estratégia utilizada tanto para obter a adesão do leitor (no caso, a criança a quem o livro se destina), ao mostrar que as diferenças são parte de seu cotidiano (observe-se o uso do nós inclusivo), quanto para assinalar quais sujeitos estariam em desvantagem e, portanto, necessitariam de atenção. Além disso, nos paratextos examinados há também aqueles que posicionam o diferente à distância - temporal, geográfica, cultural-, e, nesses casos, as histórias visam informar, surpreender ou dar relevo ao exotismo desses "outros". Assim, no Livro 15, a protagonista convida o leitor a seguir numa aventura, passeando pela história brasileira, para "descobrir coisas incríveis" (no caso, o extraordinário consiste no encontro com o líder Zumbi).

Nas obras que tematizam a diferença indígena, frequentemente se acentuam certas marcas de exotismo ou, por vezes, são descritas práticas curiosas que diferem do cotidiano dos leitores presumidos. Na sinopse do Livro 16, apresentada na contracapa, afirma-se que, "ao ler essas histórias, você, que mora 
na cidade, poderá ter uma ideia de como é a vida nas aldeias". No Livro 20, o paratexto explica que o autor "pretende aproximar o leitor a um Brasil distante, mas muito brasileiro e mágico-poético". E ainda, na Série L, um texto introdutório afirma que os livros apresentam "os mitos de nossos índios em linguagem acessível [...], com ilustrações inspiradas nas culturas indígenas de onde eles foram transcritos". Nas páginas finais de cada obra da série, o leitor pode informar-se sobre a localização geográfica e sobre aspectos socioculturais dos povos indígenas, dados que, ao mesmo tempo que informam, conformam e produzem as culturas descritas, atribuindo-lhe determinados significados.

Em certa medida, pode-se afirmar que a visibilidade conferida aos diferentes, em especial através de aspectos exóticos das práticas culturais, se configura numa conveniente estratégia utilizada para assegurar a variação de produtos e a diversificação de informações no espetáculo contemporâneo da cultura de consumo (Hall, 1997).

Dos recortes destacados, em que ecos do discurso multicultural se fazem ouvir, infere-se que a diferença é significada de maneiras distintas, ora como próxima de nós, ora como distante. Tais construções posicionam os diferentes como partícipes de uma mesma cultura ou de culturas distintas, que a literatura se ocupa de "traduzir" para os pequenos leitores. De um modo ou de outro, as diferenças são constituídas em relação ao olhar daquele que escreve os paratextos, que, por sua vez, incita o leitor a ler o texto principal dentro do mesmo olhar; dessa forma, vincula-o também a uma identidade referencial.

\section{O discurso informativo e científico nos paratextos}

Um aspecto que se destaca em diversos paratextos examinados é a utilização de um discurso científico voltado para informar sobre as diferenças tematizadas no texto principal da obra. A análise mostrou que, em alguns casos, são veiculados alertas ("atenção, galera, de olho na balança", Livro 10), dicas de como viver melhor (consigo mesmo e com os outros), mas tam- bém informações científicas (dados epidemiológicos; a probabilidade de um professor e/ou aluno ter em sala de aula um anão, um surdo, um Down, um cego; estatísticas e possíveis explicações para determinadas condições etc.), que parecem ter sido retiradas diretamente de um manual técnico ou, ainda, de um livro didático.

A contracapa do Livro 10 apresenta um problema que afligiria crianças e jovens nos dias de hoje: "a cobrança atual que existe sobre a própria imagem". No paratexto destaca-se que um dos objetivos da autora é "o crescimento sadio do corpo e da mente da garotada de hoje, que vê a vida passar na tela da tevê" (o destinatário visado, no caso, é o leitor adulto). Como estratégias de aproximação com o leitor, a autora afirma que sua obra "é uma conversa profunda de quem viveu, na pele e no peso, o preconceito, os apelidos, a insegurança e os 'etcéteras' de estar sempre fora do padrão de beleza" (Livro 10). Nascida "numa família mais gordinha do que magra", a autora apresenta-se como alguém que já sofreu muito com o excesso de peso e, assim, autoriza-se a falar sobre a obesidade. Como jornalista, ela também se autoriza a informar para promover a saúde. O catálogo da Editora Moderna disponível na Internet afirma que a autora "convida os jovens a analisar, com muito bom humor, os mitos sobre a obesidade infantil e indica caminhos para uma vida melhor, sem preconceito, sem neurose, estresse e com muita saúde e alto astral" (p. 1). A informação sustentada em fatos científicos, na mais tenra idade, é mostrada como "a" chave para uma vida melhor, livre de doenças e de preconceitos.

A apresentação do referido livro é feita por Fausto Silva - Faustão, conhecida personagem da televisão brasileira - e se dirige aos "gordinhos e pais dos gordinhos" da seguinte maneira:

\footnotetext{
A vida me ensinou que o ideal é dosar bem as coisas. O gordinho deve fazer um bom tratamento, desde pequeno, mas sem ficar doidão, estressado ou escravo da balança e das regras de beleza. [...] Para o gordinho fora do peso que convive com as gozações e com o preconceito no dia a dia, com os colegas da escola e os adultos enchendo a sua
} 
paciência, eu só vejo uma saída: leve tudo na esportiva, mas encare o problema de frente. (Livro 10)

Encarar o problema seria, então, reconhecer-se como gordo, buscar um tratamento para "evitar no futuro doenças como a diabete e outras que aparecem com mais frequência em quem resolveu esquecer a balança", contando com "a ajuda do seu professor, dos seus pais, de uma tia amiga, de um médico". A diferença, aqui, precisa ser corrigida o quanto antes - e isso supostamente poderia ser feito por meio do acesso à informação.

Voltado para crianças menores, ${ }^{4}$ o paratexto do Livro 1 também interpela os leitores para promover vida e alimentação mais saudáveis: "O coelhinho João vai vestir seu calção para pular na piscina, mas opa! João encolhe a barriga, aperta-a com a mão, mas não consegue fechar o botão. [...] Veja como João muda seu cardápio e aprende a se alimentar de maneira mais saudável" (Livro 1).

Alguns dos paratextos analisados - notadamente os da Coleção B - se resumem a uma grande coletânea de informações (geralmente presentes nas últimas páginas dos livros), que parece servir a inúmeros fins: justificar a escolha pelo desenvolvimento de uma história com um determinado tema inclusivo; "esclarecer" os sujeitos de modo que dirima o preconceito frequentemente associado à ignorância; mostrar aos professores, por meio de números, porcentagens e estatísticas, que a chance de ter um "diferente" na sala de aula é grande (e que é importante estar preparado para lidar com ele); ensinar os sujeitos a reconhecer sintomas, causas e modos de prevenir e/ou remediar uma determinada condição. Destaca-se, a seguir, um paratexto focado num discurso matemático/estatístico claramente direcionado para o leitor professor:

Baixa visão: estima-se que $2 \%$ das pessoas apresentem deficiência visual. Isso representado na realidade escolar

${ }^{4}$ Conforme informações em <www.lendoeaprendendo. sp.gov.br>, essa obra fez parte do acervo do Programa Nacional de Livro Didático (PNLD) em 2006. demonstra que a chance de termos um aluno com deficiência visual é muito grande. [...] Uma pessoa com baixa visão precisa de ajuda técnica para ter as mesmas oportunidades de todos. Isso muitas vezes pode ser resolvido com óculos bem adaptados. (Livro 4)

O discurso matemático/estatístico institui a norma e, portanto, também o desvio - trata-se de um discurso tão poderoso que mesmo os irrisórios $2 \%$ referidos dão um ar de veracidade e relevância ao problema da baixa visão nas salas de aula. Além disso, a diferença é mostrada como algo que pode (e deve) ser corrigido com o auxílio de especialistas, "óculos bem adaptados" etc. O paratexto a seguir coloca em relevo certas maneiras de narrar e de caracterizar sujeitos diagnosticados como tendo transtorno de deficit de atenção com hiperatividade (TDAH), utilizando também dados estatísticos:

\footnotetext{
A prática tem demonstrado que $3 \%$ a $5 \%$ das crianças em idade escolar podem ser incluídas nesse diagnóstico. [...] O TDAH na infância, em geral, associa-se a dificuldades na escola e no relacionamento com as demais crianças, pais e professores. As crianças são tidas como "avoadas", "vivendo no mundo da lua" e, geralmente, "estabanadas" e com "bicho carpinteiro" ou "ligados na tomada" (isto é, não param quietas por muito tempo). (Livro 7)
}

Assumindo um teor aparente "informativo", tal texto, que descreve as crianças com TDAH como "avoadas", "impulsivas", “com problemas de comportamento" e "desatentas", acaba por constituí-las dessas formas - porque é a linguagem que torna possível "aquilo que somos e aquilo em que podemos nos tornar" (Woodward, 2007, p. 17). Aliás, cabe ressaltar que a própria condição em questão não existiria $a$ priori na natureza, mas seria (contínua e insistentemente) produzida pelo discurso biomédico, pelos discursos psi (psicológicos, psicanalíticos, psiquiátricos, psicopedagógicos, entre outros), pelo discurso midiático, entre outros.

Os paratextos da referida coleção também funcionam como ganchos interpelativos, enfatizando a 
necessidade de as crianças "se colocarem no lugar do outro", para combater o preconceito - mas o que acaba acontecendo é que, em diferentes obras e de modo um tanto quanto inconsistente, a autora torna triviais diferenças incomuns, a serem - de certa forma-celebradas:

E você, já viu algum anão? Já imaginou como seria a vida destas pessoas? Colocar-se no lugar de algumas pessoas nos faz tratá-las sem preconceitos. Experimente! (Livro 3)

Zilá apresentava uma deficiência física. E você, já se colocou no lugar de uma pessoa que tem dificuldades em caminhar? (Livro 2)

Você conhece alguém como o Danilo [zangão cego]? Se conhece, pergunte-lhe como ele executa algumas tarefas. Se não conhece, não sabe o que está perdendo. Todos podemos melhorar muito no convívio com a diferença. (Livro 5)

Somente um dos paratextos analisados contrapõe-se à ideia de que apenas a informação (sustentada na ciência) é capaz de redimir os sujeitos do preconceito - preferindo, ao invés disso, a indeterminação do não saber. O autor afirma: "não tenho respostas prontas. Só os tolos as têm em quantidades. Ah sim... os tolos e os preconceituosos. Eu prefiro não saber de nada e aprender com os outros" (Livro 9).

Os paratextos dos livros que trazem personagens com síndrome de Down também apresentam vinculações expressivas com discursos científicos: a análise mostrou uma recorrência no que diz respeito à enumeração daquilo que alguns livros chamam de "traços típicos" ou características da pessoa com síndrome de Down - mãos pequenas, dedos curtos, olhos puxados, orelhas pequenas e com inserção baixa, rosto oval, estatura menor, tônus muscular reduzido, flacidez muscular, cabelo liso e fino, olhos com linha ascendente e dobras da pele nos cantos internos ("semelhantes aos orientais"), nariz pequeno e um pouco achatado, rosto redondo, pescoço curto e grosso etc. Tal enunciação sistemática de características e modos de ser, embora feita (às vezes) de modo informativo e quase jornalístico, às vezes de modo científico (porque racional e com aura de neutralidade, como se não houvesse um processo inevitável de seleção na apresentação dos "fatos"), não é neutra, pois produz efeitos nos sujeitos envolvidos (sejam eles pais, professores, crianças). Há, aparentemente, um motivo plenamente justificado para que ocorra tal enumeração: tanto o discurso científico quanto o informativo estão pautados na máxima da prevenção.

Vê-se ainda que, nos paratextos, não há menção a desconfortos relacionados às características supracitadas, já que elas são consideradas meras "variantes genéticas" (como altura, peso, cor dos olhos etc.) e, pelo discurso científico, tais variações estariam previstas na "ordem da natureza" ou, ainda, na "grande ordem genética das coisas". Além disso, passa-se a ideia de que tais "variantes genéticas" estariam "em todos nós" e nos atingiriam igual e inexoravelmente, obedecendo às leis da natureza e, claro (!?), às leis da probabilidade. Destaca-se, para exemplificar tal questão, o seguinte excerto:

\footnotetext{
A síndrome de Down afeta aproximadamente uma em cada 550 crianças. Todas as pessoas estão sujeitas a ter um filho com síndrome de Down, independente da raça ou condição socioeconômica. Ainda não se conhece a causa dessa alteração genética, mas já se sabe que não existe responsabilidade do pai ou da mãe para que ela ocorra. Sabe-se também que problemas ocorridos durante a gravidez, como fortes emoções, quedas, uso de medicamentos ou drogas não são causadores da síndrome de Down, pois ela já está presente logo na união do espermatozoide (célula do pai) com o óvulo (célula da mãe) [...]. (Livro 6)
}

O texto propõe-se a informar sobre a prevalência da doença; o risco de ela poder-se manifestar em todas as famílias, sem exceção; a tentativa de estabelecimento de causas, culpas e responsabilidades; e a menção ao discurso do senso comum, utilizado com frequência para explicar a síndrome. O que salta aos olhos é o modo como os paratextos informativos silenciam no que diz respeito ao retardo mental (e à 
microcefalia e ao baixo peso do cérebro) na síndrome de Down - mencionando, em grande parte dos casos, que o afetado "é igual a todo mundo", "aprende como todo mundo" e se "desenvolve naturalmente" -, bem como o modo como o discurso biomédico acaba atribuindo positividade a essa diferença, como se ela fosse apenas mais um traço distintivo, como qualquer outro, da espécie humana. Em alguns casos, defendese a ideia de que a síndrome de Down não é uma doença, e o Livro 8 justifica assim tal afirmação:

Veja bem: as doenças, na maioria das vezes, saram quando tomamos remédios ou ficamos em repouso por algum tempo. Mas isso não acontece com certas síndromes, que apenas fazem algumas pessoas terem seus organismos construídos de um jeito um pouco diferente, e por isso também vão ter algumas características diferentes. (Livro 8)

O paratexto do Livro 12 aproxima a síndrome de Down a um personagem bastante conhecido pelas crianças:

\footnotetext{
Sabia que há crianças que nascem bem parecidas? Os olhinhos são meio puxados, os dedinhos das mãos e dos pés são menores, a língua é grande, e costumam ser muito alegres e carinhosas. São crianças que nascem com síndrome de Down. [...] E sabe de uma coisa? Elas não crescem. Quer dizer, o corpo cresce, mas elas continuam um pouco crianças, sempre. Na escola elas também são muito inteligentes, mas aprendem números e letras em outro ritmo. E adoram aprender com música! Você já pensou que essa é uma outra forma de aprender? Se a gente pudesse dar um nome legal para essas crianças, ele seria "crianças Peter Pan", já que elas não querem crescer. (Livro 12)
}

As afirmações contidas nesse excerto parecem mesclar um discurso médico - que ensina a identificar a diferença - com um discurso multiculturalista que, omitindo conflitos e vetores de força, busca conferir um sentido positivo para a síndrome. A estratégia utilizada para marcar a diferença e, ao mesmo tempo, ressignificá-la, é chamar de crianças Peter Pan os portadores da síndrome de Down, afirmando que, tal como o personagem de livros, filmes e animações amplamente divulgadas, essas crianças teriam escolha, mas optariam por "não crescer", mantendo "no coração a doçura e a ingenuidade da infância". Seria oportuno indagar acerca dessa estratégia: Como esses paratextos supõem que sejam os seus leitores crianças? Quais efeitos produzem tais estratégias utilizadas para conquistar a adesão a determinados temas, abordagens, discussões, atitudes, condutas?

\section{Atando as pontas}

Findo esse rápido sobrevoo sobre alguns paratextos de livros sobre diferença voltados para o público infantil, é hora de buscar atar alguns fios analíticos.

Ora direcionados ao destinatário "maior" - o adulto, em especial o professor (que se depara com as diferenças na sala de aula ou é pressionado pedagogicamente para tais abordagens), ora voltados para o leitor último - a criança -, os paratextos constituem um invólucro sedutor para a escolha e leitura de livros que abordam as diferenças. Nesse processo persuasivo, eles também servem para reforçar ideias e conceitos, para situar a diferença e ensinar sobre ela, para dizer quem e como são os diferentes, para prescrever atitudes e para lembrar que a temática concerne a todos nós, já que está presente em nosso dia a dia.

A análise de tais produções mostrou que as diferenças vão sendo constituídas e significadas de maneiras múltiplas, mas em boa parte os argumentos utilizados para informar, persuadir e cativar o leitor entrelaçam discursos científicos e multiculturalistas e lançam mão de algumas antigas estratégias do gênero, como a utilização de personagens animais. Os paratextos compõem determinadas maneiras de falar dos sujeitos tidos como diferentes e muitas vezes se alinham à despreocupação dos autores em relação à literariedade e à dimensão estética do texto, no qual se erige como eixo central uma certa educação para a diferença. Nessa dimensão, a articulação dos discursos científico e multicultural enfatiza a temática central do livro e, ao mesmo tempo, confere-lhe credibilidade, uma vez que é nesse invólucro da história que os au- 
tores e editores virtualmente dialogam com os leitores; é com "despretensiosa" atitude que eles acenam quase sempre para uma definição da própria obra e para uma forma preferencial de lê-la.

Em síntese: tais paratextos não são acessórios neutros ou ornamentos da edição; exercem uma orientação e uma pedagogia claras, apontando para uma definição da própria obra e para a forma preferencial e "adequada" de lê-la.

\section{Referências bibliográficas}

BAUMAN, Zygmunt. Em busca da politica. Rio de Janeiro: Jorge Zahar, 2000.

BHABHA, Homi K. O local da cultura. Belo Horizonte: Editora UFMG, 2005.

CHARAUDEAU, Patrick; MAINGUENEAU, Dominique. Dicionário de análise do discurso. São Paulo: Contexto, 2004.

COLOMER, Teresa. A formação do leitor literário. São Paulo: Global, 2003.

FERREIRA, Norma Sandra de Almeida. Livros infantis: uma estratégia editorial. In: FERREIRA, Norma Sandra de Almeida (Org.). Livros, catálogos, revistas e sites para o universo escolar. Campinas: Mercado de Letras/Associação de Leitura do Brasil, 2006. p. 137-152.

HALL, Stuart (Org.). Representation. Cultural representations and signifying practices. London: Thousand Oaks; New Delhi: Sage Publications/Open University, 1997.

KIRCHOF, Edgar; SILVEIRA, Rosa M. Hessel. Professoras moralizadoras, normalizadoras ou ausentes $-\mathrm{A}$ literatura infantil retratando as diferenças. Anuário de literatura, v. 13, n. 2, p. 56-75, 2008. Disponível em: <http://www.periodicos.ufsc.br/index.php/ literatura/issue/current/showToc $>$.

MAINGUENEAU, Dominique. Análise de textos de comunicação. São Paulo: Cortez, 2001.

SHAVIT, Zohar. Poética da literatura para crianças. Lisboa: Caminho, 2003.

WOODWARD, Kathryn. Identidade e diferença: uma introdução teórica e conceitual. In: SILVA, Tomaz Tadeu da (Org.). Identidade e diferença: a perspectiva dos estudos culturais. 3 ed. Petrópolis: Vozes, 2007. p. 7-72.

YÚDICE, George. Cultura e educação no novo entorno. In: SOMMER, Luis Henrique; BUJES, Maria Isabel E. (Orgs.).
Educação e cultura contemporânea: articulações, provocações e transgressões em novas paisagens. Canoas: Editora da ULBRA, 2006. p. 11-21.

\section{Livros infantis citados}

Coleção A: Os Outros e Eu

Livro 1: DOINET, Mimi. João não cabe mais em seu calção. São Paulo: Larousse do Brasil, 2004.

Coleção B: Ciranda das Diferenças

Livro 2: HONORA, Márcia. O problema da centopeia Zilá. São Paulo: Ciranda Cultural, 2008.

Livro 3: HONORA, Márcia. Nem todas as girafas são iguais. São Paulo: Ciranda Cultural, 2008.

Livro 4: HONORA, Márcia. O charme de Tuca. São Paulo: Ciranda Cultural, 2008.

Livro 5: HONORA, Márcia. Uma formiga especial. São Paulo: Ciranda Cultural, 2008.

Livro 6: HONORA, Márcia. Uma amiga diferente. São Paulo: Ciranda Cultural, 2008

Livro 7: HONORA, Márcia. A escola da tia Maristela. São Paulo: Ciranda Cultural, 2008.

Coleção C: Igualdade na Diferença

Livro 8: HUAINIGG, Franz-Joseph; BALLHAUS, Verena. Juntos somos ótimos. São Paulo: Scipione, 2007.

\section{Coleção D: Girassol}

Livro 9: BRAZ, Júlio Emílio. Felicidade não tem cor. 2. ed. São Paulo: Moderna, 2002.

Livro 10: CORRÊA, Leonor. De cara com o espelho. São Paulo: Moderna, 2003.

Coleção E: Muriqui Júnior

Livro 11: MARTINS, Georgina. Minha família é colorida. São Paulo: Edições SM, 2005.

Livro 12: PERLMAN, Alina. Diferentes somos todos. São Paulo: Edições SM, 2005.

\section{Coleção F: Camaleão}

Livro 13: BELINKY, Tatiana. Diversidade. São Paulo: Quinteto Editorial, 1999.

Coleção G: Magia das Letras

Livro 14: BRAZ, Júlio Emílio. O muro. São Paulo: Paulinas, 2003. 
Coleção H: Aventuras de Luana

Livro 15: MACEDO, Aroldo; FAUSTINO, Oswaldo. Luana: as sementes de Zumbi. São Paulo: FTD, 2007.

\section{Coleção I: Pawana}

Livro 16: GRUPIONI, Luís Donisete Benzi. Juntos na aldeia. São Paulo: Berlendis \& Vertecchia, 2004.

Coleção J: Sinto Tudo Isso e Mais um Pouco

Livro 17: CAMPOS, Carmen Lúcia. Não tem dois iguais. São Paulo: Escala Educacional, 2005.

Série K: Morená

Livro 18: FITTIPALDI, Ciça. Subida pro céu: mito dos índios bororo. São Paulo: Melhoramentos, 1986.

Livro 19: FITTIPALDI, Ciça. Tainá, estrela amante: mito dos índios Karajá. São Paulo: Melhoramentos, 1986.

Obras avulsas:

Livro 20: JOSÉ, Elias. (Re)fabulando: lendas, fábulas e contos brasileiros. São Paulo: Paulus, 1998.

Livro 21: LIMA, Heloísa Pires. Histórias da Preta. 2. ed. São Paulo: Companhia das Letrinhas, 2005.

ROSA MARIA HESSEL SILVEIRA, doutora em educação pela Universidade Federal do Rio Grande do Sul (UFRGS), com pós-doutorado na Universidade de Lisboa, é professora do Curso de Pedagogia e do Mestrado em Educação da Universidade Luterana do Brasil (ULBRA) e professora colaboradora convidada do Programa de Pós-Graduação em Educação da UFRGS. Publicações mais importantes: Professoras que as histórias nos contam (Rio de Janeiro: DP\&A, 2002); Cultura, poder e educação (Canoas: Editora da ULBRA, 2005) e Estudos culturais para professor@s (Canoas: Editora da ULBRA, 2008). Pesquisa em andamento: "Narrativas, diferenças e infância contemporânea", financiada pelo CNPq.E-mail: rosamhs@terra.com.br
IARA TATIANA BONIN, doutora em educação pela Universidade Federal do Rio Grande do Sul (UFRGS), é professora do Curso de Pedagogia e do Mestrado em Educação da Universidade Luterana do Brasil. Publicações recentes: Trajetórias e processos de ensinar e aprender: políticas e tecnologias (Porto Alegre: EDIPUCRS, 2008); Cultura, identidades e formação de professores: perspectivas para a escola contemporânea (Canoas: Editora da ULBRA, 2008); Narrativas sobre diferença indígena: como se produz um "lugar de índio" no contexto escolar (Revista Brasileira de Estudos Pedagógicos, v. 89, n. 222, p. 312-324, ago. 2008). Pesquisa em andamento: "Identidades e diferenças na cena pedagógica contemporânea: índios como autores de literatura infantil”, financiada pela FAPERGS. E-mail: iara. bonin@uol.com.br

DANIELA RIPOLL, doutora em educação pela Universidade Federal do Rio Grande do Sul (UFRGS), é professora do Curso de Biologia e coordenadora do Programa de Pós-Graduação em Educação da Universidade Luterana do Brasil. Publicações recentes: Cultura, identidades e formação de professores: perspectivas para a escola contemporânea (Canoas: Editora da ULBRA, 2008); O currículo midiático, a pedagogização cotidiana do medo e o ensino de ciências: algumas reflexões e (des)construções contemporâneas (Anais... XIV ENCONTRO NACIONAL DE DIDÁTICA E PRÁTICA DE ENSINO, Porto Alegre, 2008. 1. CD-ROM); Ensaios em estudos culturais, educação e ciência (Porto Alegre: Editora da UFRGS, 2007). Pesquisa em andamento: "Biofantasias, biomanias, bioforias: as pedagogias da mídia e a espetacularização da bio(tecno)logia na contemporaneidade", financiada pelo CNPq.E-mail: daniela_ripoll@terra.com.br

Recebido em outubro de 2009 Aprovado em janeiro de 2010 
Rosa Maria Hessel Silveira, Iara

Tatiana Bonin e Daniela Ripoll

Ensinando sobre a diferença na

literatura para crianças: paratextos, discurso científico e discurso multicultural

Parte-se da onipresença da literatura infantil no cenário pedagógico e do pressuposto de que os paratextos (fragmentos verbais que acompanham o texto principal das obras) que nela ocorrem são importantes guias para a sua leitura e exercem também uma função pedagógica. Considera-se ainda que a diferença, tema de interesse contemporâneo, tem invadido a área da literatura infantil. O objetivo do estudo é analisar como esses paratextos ensinam e buscam influenciar condutas e atitudes em relação à diferença. Foram analisados paratextos de 21 títulos e esquadrinharam-se dois discursos neles presentes: o discurso multiculturalista e o discurso científico-informativo. Conclui-se que as diferenças vão sendo constituídas e significadas de maneiras múltiplas, como próximas ou exóticas ou como experiências a serem feitas; percebese que, em boa parte, os argumentos utilizados para informar, persuadir e cativar o leitor entrelaçam os discursos citados. Nos paratextos, são compostas determinadas maneiras de falar dos sujeitos diferentes alinhadas à preocupação de autores e editores em atuar numa certa educação para a diferença.

Palavras-chave: literatura infantil; diferença; paratexto.
Teaching about difference in children's literature: paratexts, scientific discourse and multicultural discourse

Our starting point is the ubiquity of children's literature in the pedagogical scenery and the assumption that paratexts (verbal fragments accompanying the main text) which appear in the literature are important guides for its reading, exercising a pedagogical function. We also consider that the contemporary subject (difference) has made inroads into children's literature. In this context, our study aims to analyse how these paratexts teach and seek to influence conducts and attitudes with relation to difference. Paratexts from 21 recent titles were analysed and two discourses were explored in them: the multicultural and scientific-informative discourses. We conclude that arguments used to inform, persuade and catch the attention of the reader intertwine the above-mentioned discourses. Determined forms of speech of the different subjects are elaborated in the paratexts, in tune with authors' and editors' preoccupation to engage in a certain education for difference.

Key words: children's literature; difference; paratext.

Enseñando sobre la diferencia en la literatura para niños: textos colaterales, discurso científico y discurso multicultural

Se parte de la omnipresencia de la literatura infantil en el escenario pedagógico y de la suposición de que los textos colaterales(fragmentos verbales que acompañan el texto principal de las obras) que en ellas ocurren son importantes guías para su lectura y ejercen también una función pedagógica. Todavía se considera que la diferencia, tema de interés contemporáneo, ha invadido el área de la literatura infantil. El objetivo del estudio es analizar cómo esos textos colaterales enseñan y 
buscan influenciar conductas y actitudes en relación a la diferencia. Fueron analizados textos colaterales de 21 titulos y se estudiaron dos discursos que estaban presentes en ellos: el discurso multicultural y el discurso cientifico informativo. Se concluye que las diferencias van siendo constituidas y con significados de múltiples maneras, como próximas o exóticas o como experiencias a ser realizadas, se nota que, en buena parte, los argumentos utilizados para informar, persuadir y cautivar al lector entrelazan los discursos citados. En los textos colaterales, son compuestas determinadas maneras de hablar de los sujetos diferentes alineadas a la preocupación de autores y editores en actuar en una cierta educación para la diferencia.

Palabras claves: literatura infantil;

diferencia; texto colateral. 